\title{
SCIENCE COMPETITIONS: DO THEY FOSTER LEARNING?
}

\author{
L. Descalço', P. Oliveira' ${ }^{1}$ \\ ${ }^{1}$ Universidade de Aveiro (PORTUGAL)
}

\begin{abstract}
Many studies have shown positive effects of gamification and serious games on teaching and learning. From 1989, we have been organizing National Science Competitions in Portugal, with participants from schools from all over the Country. In this work, we assess the impact of these competitions on student's motivation and performance in the school. The study is mainly based on surveys done on the years 2015 and 2017. Both, students and their teachers, have participated in the surveys. We also present some data about usage of the computer system used in the competitions during the event and for practicing to the event. Based on teacher's opinions we conclude the events have some positive influence on student's motivation.
\end{abstract}

Keywords: Serious games, computers in education, motivation.

\section{INTRODUCTION}

The University of Aveiro has a long tradition of using computer systems for learning and assessment. Project PmatE (see [1]), started in 1989 developing parametrized questions about equation solving and on 1991 the first mathematics competition for $7^{\text {th }}$ grade students took place. Since then, every year, University of Aveiro welcomes thousands of students from all over the country in the national science competitions (NSC). Currently NSC cover other scientific areas beyond mathematics, namely Physics, Chemistry, Biology, Geology and Portuguese supported by a web platform (PeA).

In each competition, students, in teams of two, have to answer 20 questions on curricular topics, where each question consists of an initial text together with four true/false statements related to it. The winner is the team that validates (correctly) all the eighty statements in less time.

These questions are generated by Question Generator Models (QGM), which are highly parametrized templates described in [2]. Parameters in a QGM can be text, numbers, figures, tables, etc. thus allowing each QGM to generate thousands of different questions on the same topic but preserving the difficulty level. Fig. 1 presents an example of a question generated by a QGM used in a Mathematics competition. In the game presented in this figure the team is on the first level of twenty (nível 1/20), the time remaining is 29 minutes and 34 seconds (29:34) and two lives remain (on each level the student has two trials to answer correctly).

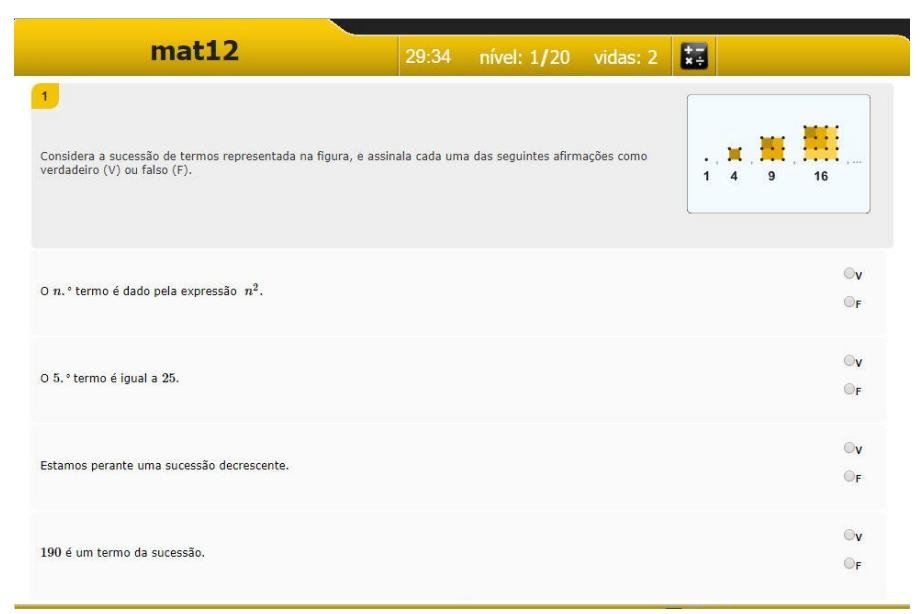

Figure 1: A question from PmatE 
As a curiosity, some teams can complete the maths tests, which means providing 80 true/false correct questions, in less than 3 minutes. This seems impossible, since they take, on average, a little more than 2 seconds to answer each question, but it happens because they take an enormous amount of time practicing for the competitions.

\section{METHODOLOGY}

We are interested in the impact of competitions on learning in general and our aim is to contribute with the case of PmatE's science competitions. To investigate the effect of these competitions on the motivation and outcomes of students from several school levels in Portugal we used surveys and data from the PeA from practice and competitions.

Schools decide if they want to participate in the competitions and if so they select their students and take them to the University of Aveiro. On the arrival, teachers go to the registration desk and in the years 2015 and 2017 they filled a questionnaire about the impact of NSC on students' motivation and learning. We analyze the teachers' answers, in a Likert scale (1-5) for two questions:

(QT1) “Do you think the competitions contribute to increase students' motivation for learning?"

(QT2) “Do you think there is some relation between students' performance in the school and their results in the competitions?"

The first question aims to confirm the perception we have that students get very motivated when they are answering questions from PmatE's tests and that it has influence on their behavior on the school. The second question contributes to investigate if PmatE's competitions have some effect on students' performance in the school. We value teachers' sensibility to these questions and, although it is just their opinion, it is somehow the best source we can get because they are in close contact with their students.

In 2015 we gathered 326 answers and in 2017, only 224. This difference lies in the fact that in 2015 teachers were surveyed from the 4 teaching cycles that participated in NSC and in 2017 only the teachers who attended the pupils of the $3^{\text {rd }}$ cycle and upper secondary education were surveyed. In addition, 1659 students in 2015 and 1902 in 2017, randomly chosen after competing, answered a questionnaire about the NSC, filled by staff members to avoid problems about readability and minimizing incomplete answers.

We analyze the data from 2 non-consecutive years, 2015 and 2017, to minimize the existence of the same students in the same school levels, and to get a broader representation.

In 2015,3531 students from the $7^{\text {th }}$ to the $9^{\text {th }}$ grades ( $3^{\text {rd }}$ cycle of basic education) and 2030 from $10^{\text {th }}$ to $12^{\text {th }}$ grades (secondary education) participated in the NSC, so our sample is $29,8 \%$ of the participants. Regarding 2017, the participation was distributed as follows: 3818 students from $7^{\text {th }}$ to $9^{\text {th }}$ grades $\left(3^{\text {rd }}\right.$ cycle of basic education) and 1787 from the $10^{\text {th }}$ to the $12^{\text {th }}$ grades (secondary education), so our sample is $33,9 \%$ of the participants.

We cannot control the number of teachers that accompanied the students because not all of them went to the registration desk, however we do know the number of schools participating in the NSC. In 2015 there were 229 schools (including the ones of primary education and $2^{\text {nd }}$ cycle education) and 326 teachers answered the questionnaire. In 2017 there were 187 schools from the $3^{\text {rd }}$ cycle and secondary education and 224 teachers were inquired, so we may assume that a large percentage of schools answered the questionnaire.

As a curiosity, regarding the number of students that are part of the educational Portuguese system we gathered some data from [5] and [6].

In 2015, there were 315950 students in Portugal (excluding the archipelagos of Madeira and Azores) enrolled on the regular education system in the $3^{\text {rd }}$ cycle, which means that $1,12 \%$ of these students participated in the event NSC this year. On secondary education there were 196380 students enrolled on the corresponding courses, however only $106208(54,1 \%)$ were enrolled on STEM areas, and as NSC for these grades are for these areas we can state that $1,9 \%$ of these students participated in the 2015 NSC edition. We get similar numbers for 2017. 


\section{RESULTS}

In this section we will analyze teachers' and students' answers to questionnaires and also data extracted from the PeA from which we infer that students are highly enrolled on these kind of games.

Since the beginning of the school year, the PeA provides tests with the same format and on the same topics of the ones used in NSC, although using in each level several different QGMs preventing memorizing the type of answer. These tests are called "training tests" that can be used either for training for the NSC or to improve students' knowledge on some of the curricular topics they are studying.

$\mathrm{PeA}$ collects data from the interactions of each user along the time, which allows us to infer some conclusions.

Figure 2 presents the number of users that accessed PeA per week in the school year of 2014/15 until the final competitions that occurred from the $10^{\text {th }}$ to the $13^{\text {th }}$ of May 2015. The two peeks are related to the pre-competition days that take place in schools by the end of February and the competitions week in May. Excluding Christmas' month the PeA registers more than 1000 users' interactions per week.

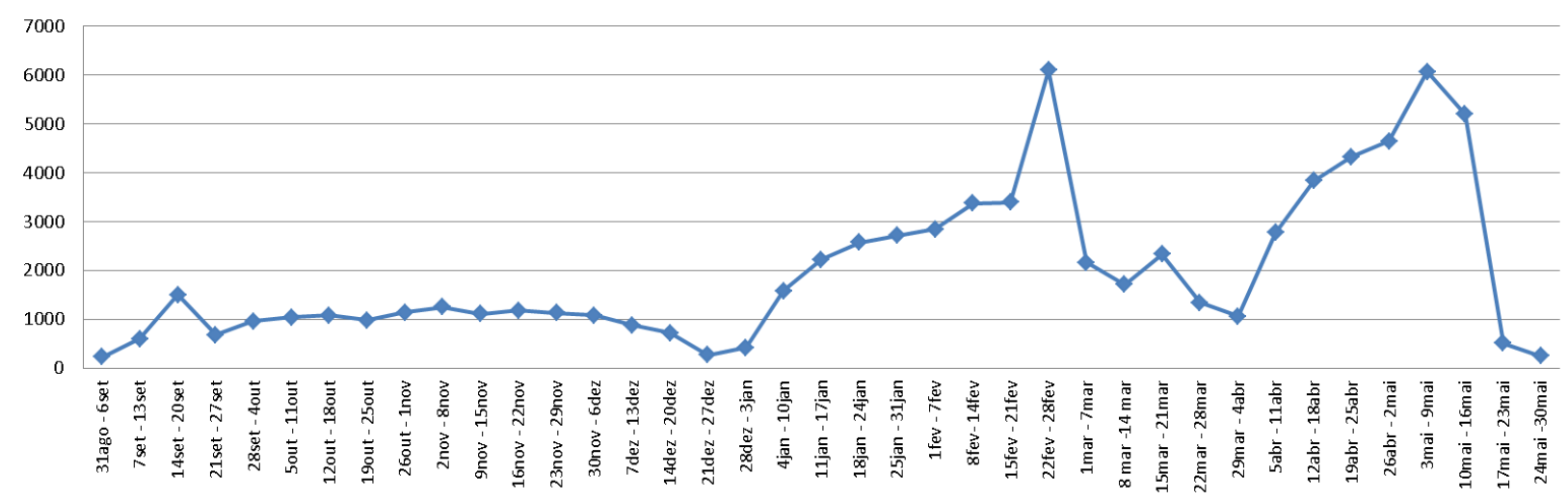

Figure 2: Number of users accessing PeA per week since 31 of August 2014 to 30 of May 2015

Regarding the school year 2016/17, the results are similar, as Figure 3 illustrates. The NSC 2017 occurred from the $8^{\text {th }}$ to the $10^{\text {th }}$ of May, which justifies the decrease in number of accesses after that period.

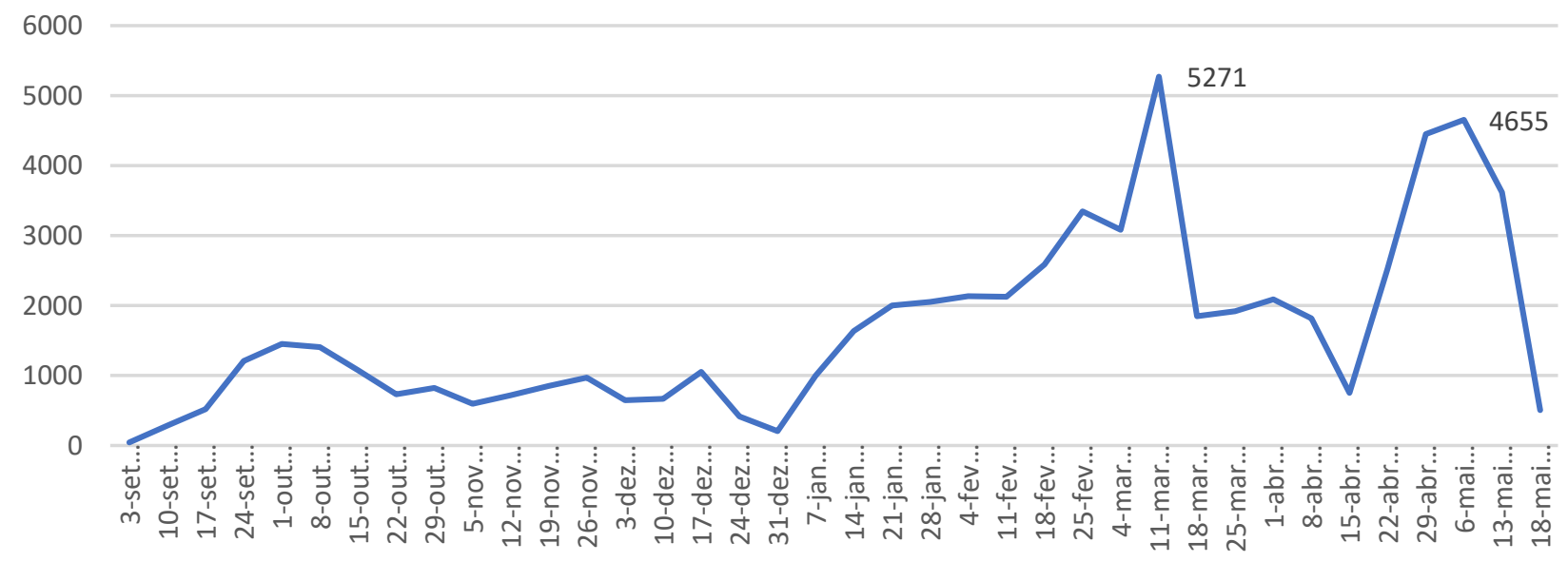

Figure 3: Number of users accessing PeA per week since 3 of September 2016 to 18 of May 2017

In 2015 the NSC received 3016 participants on the Mathematics competition Equamat, distributed by the three grades $-7^{\text {th }}$ to $9^{\text {th }}$ grade: 514 teams on the $7^{\text {th }}$ grade, 66 of them getting to the $20^{\text {th }}$ level (the best time recorded was 7 minutes and 32 seconds), 509 teams from the $8^{\text {th }}$ grade, 23 getting to the $20^{\text {th }}$ 
level (the best time recorded was 2 minutes and 16 seconds) and 485 teams from the $9^{\text {th }}$ grade, from which only 11 got to the $20^{\text {th }}$ level (the best time recorded was 7 minutes and 3 seconds).

The 2015 NSC edition had 1514 participants from secondary education, 293 teams from the $10^{\text {th }}$ grade (17 teams got to the $20^{\text {th }}$ level registering 2 minutes and 51 seconds as the best time), 259 teams from the $11^{\text {th }}$ grade (with only 5 teams attaining the level 20 and a best time of 12 minutes and 15 seconds) and 205 teams for the $12^{\text {th }}$ grade (with 5 teams on the $20^{\text {th }}$ level and the winner registering a time of 3 minutes and 59 seconds).

The analysis of number of training tests done from January to May 2015, shows that a great number of students participating in the NSC are effectively engaged in the games. For instance, the total amount of training tests performed just for the competition Equamat for $7^{\text {th }}$ grade in 2015 was 29433.

The scenario repeats itself in 2017. The NSC 2017 received 3420 participants on Mathematics competition Equamat, distributed by the three grades, $7^{\text {th }}$ to $9^{\text {th }}: 575$ teams on the $7^{\text {th }}$ grade, 79 of them getting to the $20^{\text {th }}$ level (the best time recorded was 6 minutes and 10 seconds), 539 teams from the $8^{\text {th }}$ grade, 15 getting to the $20^{\text {th }}$ level (the best time recorded was 2 minutes and 58 seconds) and 597 teams from the $9^{\text {th }}$ grade, where 21 of them got to the $20^{\text {th }}$ level and the best time recorded was 5 minutes and 50 seconds.

The 2017 NSC from secondary education edition had 1336 participants: 293 teams from the $10^{\text {th }}$ grade (26 teams got to the $20^{\text {th }}$ level registering 3 minutes and 4 seconds as the best time), 195 teams from the $11^{\text {th }}$ grade (with only 10 teams attaining the level 20 and a best time of 5 minutes and 39 seconds) and 230 teams for the $12^{\text {th }}$ grade (with 7 teams on the $20^{\text {th }}$ level and the winner registering a time of 2 minutes and 06 seconds an absolute record).

The number of students and schools accessing PeA to solve training tests is superior to the participants in the NSC (see Table 1), as there are many schools and students that use them for other purposes as testing their knowledge or even just because they like the challenge.

Table 1: Number of training tests done from January to May, 2015 and 2017

\begin{tabular}{|c|c|c|c|c|c|c|c|}
\hline & \multirow[t]{2}{*}{ Training tests ${ }^{1}$} & \multicolumn{2}{|c|}{ N. of trainings } & \multicolumn{2}{|c|}{ N. of students } & \multicolumn{2}{|c|}{ N. of schools } \\
\hline & & 2015 & 2017 & 2015 & 2017 & 2015 & 2017 \\
\hline \multirow{7}{*}{ 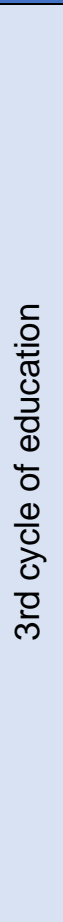 } & $\begin{array}{l}\text { EQUAmat 7th } \\
\text { grade }\end{array}$ & 26929 & 36991 & 2371 & 2703 & 221 & 234 \\
\hline & $\begin{array}{l}\text { EQUAmat 7th } \\
\text { grade (levels 1- } \\
10)\end{array}$ & 1684 & 2872 & 696 & 731 & 162 & 157 \\
\hline & $\begin{array}{l}\text { EQUAmat 7th } \\
\text { grade (levels } \\
11-20)\end{array}$ & 820 & 1284 & 564 & 476 & 155 & 138 \\
\hline & $\begin{array}{l}\text { EQUAmat 8th } \\
\text { grade }\end{array}$ & 34308 & 33354 & 1969 & 2011 & 205 & 187 \\
\hline & $\begin{array}{l}\text { EQUAmat 8th } \\
\text { grade (levels 1- } \\
\text { 10) }\end{array}$ & 877 & 1644 & 363 & 409 & 128 & 119 \\
\hline & $\begin{array}{l}\text { EQUAmat 8th } \\
\text { grade (levels } \\
11-20)\end{array}$ & 463 & 796 & 337 & 270 & 122 & 99 \\
\hline & $\begin{array}{l}\text { EQUAmat 9th } \\
\text { grade }\end{array}$ & 23880 & 25999 & 1974 & 1851 & 213 & 207 \\
\hline
\end{tabular}
1 The training tests are divided into 3 categories: one including all the 20 levels, a second one with levels from 1 to 10 and the
other including levels from 11 to 20 . 


\begin{tabular}{|c|c|c|c|c|c|c|c|}
\hline & $\begin{array}{l}\text { EQUAmat 9th } \\
\text { grade (levels } 1 \text { - } \\
\text { 10) }\end{array}$ & 678 & 910 & 346 & 284 & 130 & 106 \\
\hline & $\begin{array}{l}\text { EQUAmat 9th } \\
\text { grade (levels } \\
11-20 \text { ) }\end{array}$ & 362 & 848 & 274 & 362 & 119 & 134 \\
\hline \multirow{4}{*}{ 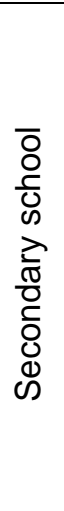 } & $\begin{array}{l}\text { mat12 10th } \\
\text { grade }\end{array}$ & 25623 & 20457 & 1169 & 1094 & 180 & 164 \\
\hline & $\begin{array}{l}\text { mat12 10th } \\
\text { grade (levels } 1 \text { - } \\
\text { 10) }\end{array}$ & 878 & 1170 & 360 & 278 & 98 & 86 \\
\hline & $\begin{array}{l}\text { mat12 10th } \\
\text { grade (levels } \\
11-20)\end{array}$ & 355 & 611 & 251 & 178 & 81 & 73 \\
\hline & $\begin{array}{l}\text { mat12 11th } \\
\text { grade }\end{array}$ & 13412 & 11402 & 806 & 711 & 112 & 146 \\
\hline
\end{tabular}

These numbers support the belief that science competitions engage students in their process of learning, and are in accordance with the answers given by either teachers or students, as we will see in the next section. Since serious games can be more effective for learning than conventional instruction (see [4]) the students' enthusiasm can have an important positive impact on learning.

\subsection{Competitions and motivation}

In Table 2 we have the results of teachers' answers for question (QT1) on 2015 | 2017 competitions. The questionnaires were filled by 326 teachers in 2015 and by 224 teachers in 2017 . The possible answers go from A1 (nothing) to A5 (a lot). In the first row the answers refer to NSC in general; in the second just for $3^{\text {rd }}$ cycle maths competitions $\left(7^{\text {th }}\right.$ to $9^{\text {th }}$ grades) and in the third row the numbers for secondary school maths competitions (school grades 10, 11 and 12).

Table 2: Motivation and NSC (teachers questionnaire) 2015 / 2017

\begin{tabular}{l|c|ccccc}
\hline & Teachers & A1 & A2 & A3 & A4 & A5 \\
\hline All & $326 \mid 224$ & $0 \mid 0$ & $7 \mid 3$ & $4 \mid 7$ & $178 \mid 101$ & $137 \mid 113$ \\
\hline Math & $256 \mid 183$ & $0 \mid 0$ & $4 \mid 2$ & $2 \mid 6$ & $148 \mid 91$ & $102 \mid 84$ \\
Math 3rd & $148 \mid 66$ & $0 \mid 0$ & $2 \mid 1$ & $2 \mid 2$ & $88 \mid 39$ & $56 \mid 24$ \\
\hline Math Sec & $60 \mid 79$ & $0 \mid 0$ & $1 \mid 2$ & $0 \mid 0$ & $40 \mid 21$ & $19 \mid 11$
\end{tabular}

In Figure 4, with the percentages of answers, we can see that almost all teachers have answered that the competitions have "some" or "a lot" of influence on students' motivation. There are some differences on answers A4 and A5 between the years 2015 and 2017. These variations occur due to the differences in our samples of the analysed years. While in 2015 the teachers inquired were from primary $\left(3^{\text {rd }}\right.$ and $4^{\text {th }}$ grades) to secondary education, in 2017 only teachers from $3^{\text {rd }}$ cycle and secondary education were inquired. 


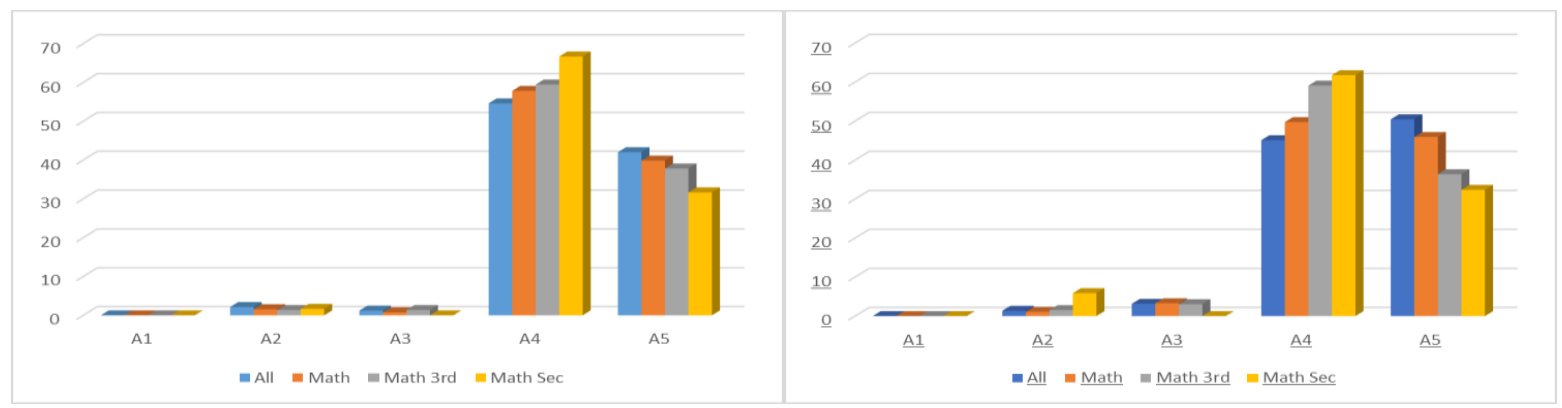

Figure 4. Motivation and NSC (teachers' answers) 2015, 2017.

\subsection{Competitions and learning}

We decided not to ask students if the competitions contributed to their motivation in school, because it is a difficult question for young people to answer, however we have included the following simple question:

(QS1) "Do you think you learn with the competitions?".

In 2015 there were 4530 students participating in mathematics competitions and 1659 answered the questionnaire, what corresponds to $36,6 \%$. In 2017 we collected 1902 from a population of 4756 students corresponding to $40 \%$.

Table 3 collects the answers to QS1 and Figure 5 presents the histograms for 2015 and 2017. The scale used varies from $A 1$ (nothing) to $A 5$ (a lot).

Table 3. Learning and NSC (students' questionnaire) 2015 / 2017

\begin{tabular}{l|c|ccccc}
\hline & Students & A1 & A2 & A3 & A4 & A5 \\
\hline All & $1833 \mid 1902$ & $96 \mid 214$ & $81 \mid 67$ & $115 \mid 88$ & $1121 \mid 1275$ & $420 \mid 258$ \\
\hline Math & $1659 \mid 1751$ & $79 \mid 195$ & $72 \mid 65$ & $105 \mid 77$ & $1001 \mid 1164$ & $402 \mid 250$ \\
Math 3rd & $1112 \mid 1162$ & $44 \mid 138$ & $51 \mid 48$ & $80 \mid 50$ & $621 \mid 745$ & $316 \mid 181$ \\
\hline Math Sec & $547 \mid 589$ & $21 \mid 57$ & $21 \mid 17$ & $25 \mid 27$ & $380 \mid 419$ & $86 \mid 69$
\end{tabular}

We see that most students think they learn with the competitions, but they don't believe they learn a lot. This is quite natural because the learning outcomes rise from the practice and not directly from the competition itself. After mastering the subjects asked in the training tests, students practice to find a pattern of answering as fast as possible. The winner of Mat12 $12^{\text {th }}$ grade in 2017 used the technique of validating carefully the first three statements and the fourth by chance. If he lost one life in that level he only had to change the last answer. Usually the same statement is used either on the affirmative or in the negative forms, so the respondents must read carefully the statements before validating them.

From 2015 to 2017, there is a decrease in the percentage of answers A5 and an increase in answers A1. Nevertheless, there is also an increase in answers A4 and the results are very similar. The most relevant information these histograms show is that most students think they learn, although not a lot, with the competitions.

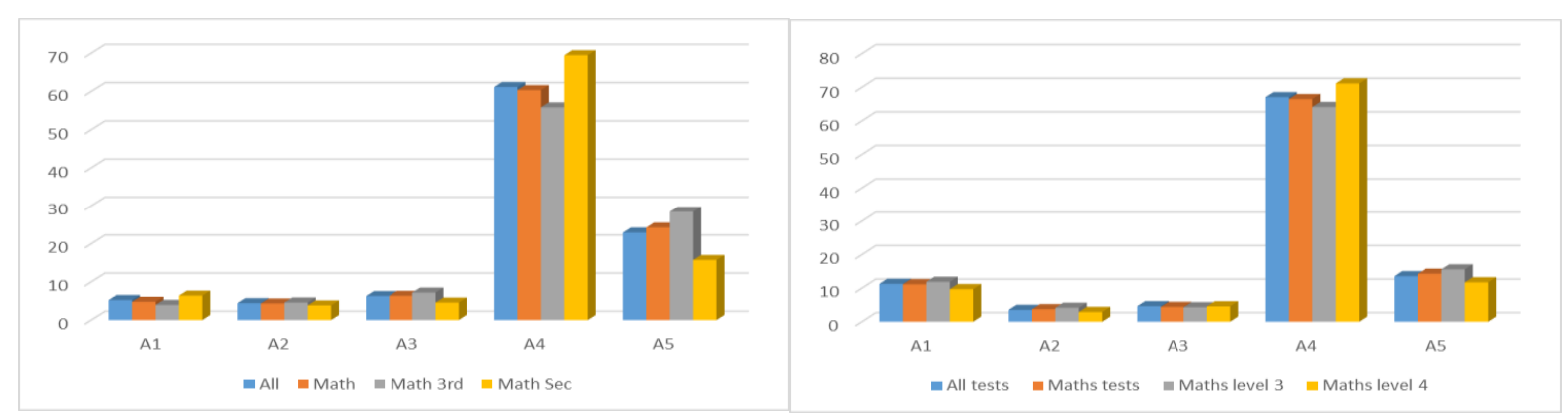

Figure 5: Learning and NSC (students' questionnaire) 2015, 2017 
Regarding (QT2) "Do you think there is some relation between student's performance in the school and their results in the competitions?" the teachers' answers are collected in Table 4 and the histograms for these answers are presented in Figure 6. The Likert scale used ranges from A1: "not at all" to A5: "Absolutely".

Table 4: Learning and NSC (teachers' questionnaire) 2015 / 2017

\begin{tabular}{l|c|ccccc}
\hline & Teachers & A1 & A2 & A3 & A4 & A5 \\
\hline All & $326 \mid 224$ & $1 \mid 0$ & $16 \mid 5$ & $21 \mid 13$ & $193 \mid 132$ & $95 \mid 74$ \\
\hline Math & $256 \mid 183$ & $1 \mid 0$ & $10 \mid 5$ & $19 \mid 11$ & $156 \mid 107$ & $70 \mid 60$ \\
Math 3rd & $148 \mid 66$ & $1 \mid 0$ & $4 \mid 2$ & $15 \mid 6$ & $87 \mid 38$ & $41 \mid 20$ \\
\hline Math Sec & $60 \mid 34$ & $0 \mid 0$ & $4 \mid 2$ & $2 \mid 0$ & $40 \mid 21$ & $14 \mid 11$
\end{tabular}

Approximately $60 \%$ of the respondents believe that the performance in the competitions and in school is related, however we remark that the students inquired have average grades of 4 in 5 for $3^{\text {rd }}$ cycle and above 15 in 20 for secondary education students. This fact allows us to conclude that the majority of students participating in NSC has good grades in general.

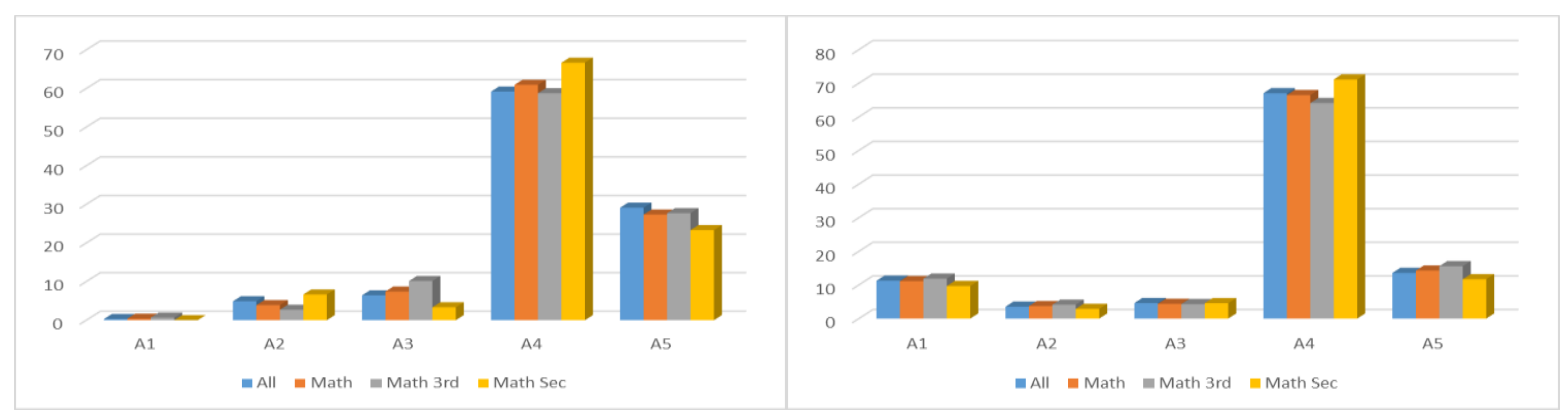

Figure 6: Learning and NSC (teachers' questionnaire) 2015, 2017

\section{CONCLUSIONS}

Based on the opinions of the teachers who answered the questionnaire, PmatE's competitions have clearly some contribution for students' motivation for learning. Of course, if we are inquiring teachers that have decided to come with their students to the competitions, we expect them to see something positive about the event. Hence, we are interested in realizing to what extent do teachers consider that one of the positive effects is regarding students' motivation. The data in the histograms and graphs is the answer to this question.

Data from the PmatE platform shows that some students spend a lot of time practicing for the competitions. Students are free to use the platform whenever they want and so this suggests that some students are very motivated in the preparation for the competitions. Although it is a serious game, based on curricular subjects, after mastering these subjects they keep on practicing, improving the amount of time spent on answering. This fact is supported by the data collected in PeA.

The best students get very fast in answering the questions that may occur in the competitions and are in fact developing a specific skill for being good on these games.

According to teachers' opinions, there is a relation between the performance in school and the results attained in the competitions. This information is important since teachers answer considering all their students and not only those that participate in the competitions.

Since students participating in the competitions are pre-selected among the best students in their schools, they are all above average and their results in the school are not very different. Therefore, we were not expecting a correlation between their results in school and the results in the competitions. Another reason is that, for similar level students, it is the practice time in PeA that determines their performance in the competitions. 
The role of competitions in education is thoroughly analysed by Tom Verhoeff in [3], where he claims that "In spite of the contradictory opinions about the relevance of competitions to education and about how to conduct such competitions, I believe that the availability of good competitions is beneficial for education in almost any discipline. A good competition should challenge the participants to give their best, or preferably more than that. If the regular curriculum is not sufficiently challenging, then good students should be encouraged to participate in extracurricular competitions."

We believe that several approaches can be combined (see [5]). For some individuals competitions are crucial for their motivation and effective learning, however combining competition, collaboration and individual study might be a key to success.

\section{ACKNOWLEDGEMENTS}

This work was supported in part by the Portuguese Foundation for Science and Technology (FCTFundação para a Ciência e a Tecnologia), through CIDMA - Center for Research and Development in Mathematics and Applications, within project UID/MAT/04106/2013.

\section{REFERENCES}

[1] Projeto Matemática Ensino, Accessed 19 March, 2018. Retrieved from https://pmate.ua.pt/

[2] P. Oliveira, P. Carvalho and J. D. Vieira, "Modelo Gerador de Questões", IADIS Conferencia Ibero-Americana WWW-Internet, 2004.

[3] T. Verhoeff, "The Role of Competitions in Education", Future world: Educating for the 21st century, pp. 1-10, 1997.

[4] P. Wouters, C. van Nimwegen, H. van Oostendorp and E. D. van der Spek, "A meta-analysis of the cognitive and motivational effects of serious games." Journal of Educational Psychology, vol. 105(2), pp. 249-265, 2013.

[5] D. W. Johnson and R. T. Johnson, Learning together and alone: Cooperative, competitive, and individualistic learning (2nd ed.), Englewood Cliffs, NJ, US: Prentice-Hall, Inc., 1987.

[6] Direção Geral de Estatísticas em Educação e Ciência, Direção de Serviços de Estatísticas em Educação and Divisão de Estatísticas do Ensino Básico e Secundário, Educação em Números Protugal 2017, Direção-Geral de Estatísticas da Educação e Ciência, 2017.

[7] PORDATA, Base de dados Portugal Contemporâneo, Accessed 26 April, 2018. Retrieved from https://www.pordata.pt/ 